\title{
5. A Critical Systems Thinking Perspective for IS Adoption
}

\author{
Syed Arshad Raza \\ Edith Cowan University \\ Craig Standing \\ Edith Cowan University
}

\section{Abstract}

Information systems (IS) project management is a challenging task. Lack of user support and involvement are among the key reasons for IS/IT project failure. The established information technology adoption models-like TAM, TAM2 and similar - only consider technology adoption from an individual user's viewpoint, highlighting key factors and their relationships, but they do not provide any mechanism to deal with multiple user perspectives and their roles in a holistic framework from a project management viewpoint. This chapter proposes a model for information system adoption based on critical systems thinking (CST) in an organisational context from a management perspective. The authors, considering IS adoption as a multiphase innovation project, argue that boundary considerations using a multiple stakeholder perspective (boundary critique) provide an alternative focus for IS adoption. The chapter uses the five basic phases or activities for information system development of the system development life cycle (SDLC). The model integrates the traditional SDLC with the ongoing process of 'phase-stakeholder-identification'. The emerging systemic stakeholder networks are proposed to be applied with network mechanisms to influence stakeholders' attitudes towards IS adoption. The study suggests that the proposed model has the capacity to serve as a roadmap for smoother IS adoption by facilitating organisational learning and change.

\section{Introduction}

Failures in information systems (IS) or information technology (IT) projects quite frequently occur, indicating the challenging nature of the IS/IT project management task (Azzara and Garone, 2003; Chen and Latendresse, 2003). Standing et al. (2006), among many others, have identified the major reasons for 
such failures as the lack of user support and involvement, lack of support and commitment of executive management, imprecisely defined project objectives and poor project management and leadership.

The application and use of IT in organisations have been extensively researched over the past few decades. The technology acceptance model, or TAM (Davis, 1989; Davis et al., 1989), has significantly contributed to the organisational know-how related to user acceptance of technology. TAM was later extended to TAM2 (Venkatesh and Davis, 2000) and the unified theory of acceptance and use of technology, or UTAUT (Venkatesh et al., 2003), but despite providing an insight into the key factors and their relationships that influence user acceptance of IT in organisations, these models do not provide any mechanism showing how an organisation can successfully proceed in IS adoption by taking multiple stakeholder perspectives and their roles of involvement into account. On the other hand, IS methodologies like the waterfall, prototyping and evolutionary models fall short of addressing issues of perception, expectancy, internal or external politics and cognitive processes that can result in IS project failure (Yardley, 2002).

This chapter aims to provide a methodological model for IS adoption in an organisational context from a critical systems thinking perspective. We consider IS adoption using Ulrich's notion of boundary considerations (boundary critique), which involves multiple stakeholders, because we believe that it can effectively help in addressing the challenges of IS adoption and provide for smoother organisational learning and change. Information systems adoption is regarded here as a multiphase innovation project, and an information system adoption model using the phases of systems development life cycle (SDLC) is proposed as an example and our model is based on concepts related to network stakeholder theory, critical systems thinking (CST) and innovation diffusion. It should be noted that the chapter uses the terms IS and IT interchangeably.

The chapter comprises four main sections. The first section analyses the literature and highlights the concepts that underpin the proposed model; the second presents the proposed model; the third discusses its implications; and the last section focuses on limitations and overall conclusions.

\section{Literature Analysis}

\section{A Management Perspective of the Stakeholder Theory}

Stakeholders are a consistent presence in any organisational life cycle (Rowley 1997). It was Freeman who brought stakeholder theory into the mainstream of 
management literature, defining a stakeholder as any group or individual who can affect or is affected by the achievement of the firm's objectives (Freeman, 1984). He conceptualised the firm or the focal organisation (FO) as the hub of a wheel and stakeholders as the ends of spokes around it, as depicted in Figure 5.1 .

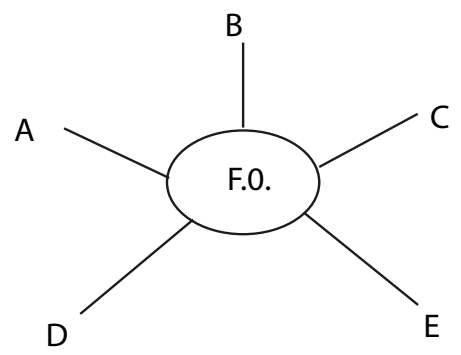

\section{Figure 5.1 Freeman's Hub-and-Spoke Model}

But Freeman's (1984) hub-and-spoke model, as mentioned by Rowley (1997), could not portray a realistic picture because:

1. it is highly likely that direct relationships among stakeholders exist, which means there is in fact a network of stakeholders and their influences

2. firms do not simply respond to each stakeholder individually; rather, they respond to multiple influences from the entire stakeholder set or a group of stakeholders

3. the organisation does not necessarily lie at the centre of the network, but is rather a stakeholder in its relevant social system or network of stakeholders.

The original model was therefore extended by Freeman and Evan (1990), emerging as a series of multilateral contracts among stakeholders and giving birth to a network of stakeholders, as shown in Figure 5.2. Thus, explaining an organisation's response to its stakeholders requires an analysis of a complex and interdependent array of relationships among stakeholders and their roles rather than just their individual relationships with the organisation.

This refined and extended view of stakeholders by Freeman and Evan (1990) forms the basis of the network of stakeholders, which we call the 'systemic stakeholder network' for our proposed model, as shown in Figure 5.5. This network involves stakeholders and the roles they play during various IS development phases. 


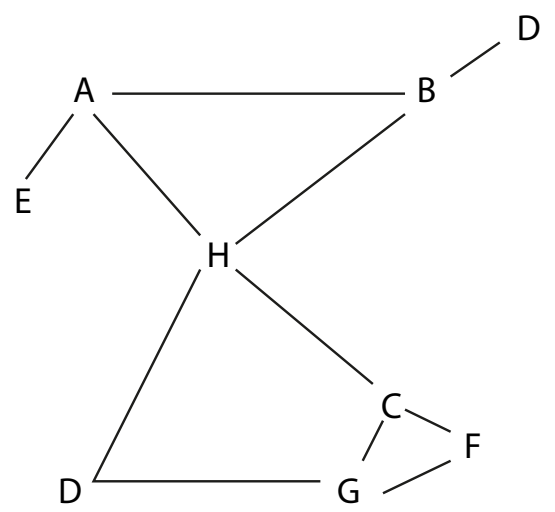

Figure 5.2 Network of Stakeholders

\section{Systems Thinking and Critical Systems Thinking (CST)}

Systems or holistic thinking views a system as a whole, focusing on how its parts affect the whole through their interactions (Ackoff, 1995) and studying their multiple cross-level interactions over time (Waldman, 2007). Critical systems thinking (CST), proposed by Ulrich (1983), is a systems thinking-based framework for a reflective practice that considers a social system design by defining its boundary as those who are involved in and affected by it. It moved Churchman's (1970, 1979) understanding of systemic boundary analysis in a new and challenging direction termed 'boundary critique' (Midgley, 2007). This chapter applies this approach to IS adoption in an organisational context.

The concept of 'boundary critique' is based on the idea of whole systems improvement (Achterkamp and Vos, 2007). It aims to include or sweep-in the maximum amount of information into the defined system boundary for analysis, on one hand, and poses the question of the rational justification of this boundary through a debate between stakeholders on the other, thus making it an ethical process involving multiple viewpoints. A different system boundary might result in a different problem analysis and, accordingly, in different solutions or changes. Wilby (2005) argues that the goal of holistic study is not to sweep-in or include everything involved; rather, it is about deciding what is relevant to the study and what is not and understanding the reasons for those choices. The choices are affected by biases and interests about what is likely to be included in the system and what is considered to be the system's environment. For example, if a car, producing the desired level of power output, is causing environmental pollution because of the unhealthy composition of its emissions then sweepingin the environmental safety consideration into the boundary of analysis might lead to an entirely opposite system evaluation outcome. 
Ulrich (1983) provides practical guidelines that both planners and ordinary citizens can use equally proficiently to conduct boundary critique. For this purpose, he offers a list of 12 questions that can be employed by those involved in and affected by the working out of what the system currently is and what it ought to be. The boundary consideration thus coherently defines what issues are to be included or excluded and who is to be involved (the stakeholders) with these issues (Midgley, 2003).

Technology in organisations, according to Malmsjö and Övelius (2003), is related to systems that use specific methods to process matter or information. This results in products that satisfy the needs of different stakeholders in society. It is, therefore, quite critical to identify stakeholders and discover how IS adoption is looked at through the eyes of those involved in and/or affected by it. From an IS adoption perspective, those involved can have an influence on the achievement of the objectives of the adoption process whereas those affected are influenced by the achievement of these objectives.

\section{Change Management and Innovation Diffusion}

Through a detailed literature analysis, Malmsjö and Övelius (2003) have identified change factors that influence IS in organisations. They have classified these into 'internal' and 'external' factors. Hall and Hord (2006), however, indicate that the success of a change process depends less on whether the source of change is internal or external. Rather, it depends more on the degree of openness and readiness of an organisation to consider the actions being undertaken and continually to examine ways to learn.

Hall and Hord (2006) view change as an innovation diffusion process rather than an event. The dynamic nature of IS necessitates that organisations and researchers understand and manage diffusion of innovations (Nilakanta and Scamell, 1990). Innovation is defined as an idea, a practice or a material artefact (product) such as a computer that is perceived to be new by the relevant unit of adoption (Hall and Hord, 2006; Zaltman et al., 1973). Innovation diffusion, according to Rogers (1995), is the process by which an innovation is communicated among the members of a social system through certain channels over time.

Innovation diffusion is often a victim of poor change management as organisations fail to realise that the resistance offered by people is not necessarily to the change per se, but the way they are treated and the roles they play in the change process (Cooper and Markus, 1995). Organisational participants who are vaguely aware of the process can cause rumours and anxiety resulting in attitudes different from those intended by management and which ultimately lead to resistance (Jick, 1993). 
Our proposed model identifies stakeholders and their roles over time, and uses the emerging stakeholder network for diffusing information about the IS project to influence attitudes. The details of the model are given in the next section.

\section{A Proposed Model for IS Adoption}

This section first formulates the basic principles, based on the literature, needed to lay the foundations of the IS adoption model. It then presents the model itself by integrating the systems development life cycle (SDLC) with concepts related to critical systems thinking (CST), network stakeholder theory and innovation diffusion.

Grounded upon the reviewed literature, we formulate the following two basic principles.

\section{Principle 1}

Information systems adoption is a multiphase innovation project, consisting of a series of steps viewed as change processes, not events (Hall and Hord, 2006; Rogers, 1995).

\section{Principle 2}

Change is by definition a dynamic process (Cao et al., 2003) that makes identification of stakeholders and their roles an ongoing process based on organisational learning, often resulting in the redefinition of boundaries of the system as the IS adoption process progresses.

\section{Composition of the Proposed Model}

This subsection discusses the components that constitute our proposed IS adoption model.

\section{Methodology}

Unlike software, information systems are never off-the-shelf as they revolve around a company's people (stakeholders) and procedures (Kroenke, 2009). As per principle one, IS adoption is viewed as a purposeful innovation project and the diffusion of an innovation is viewed as a phased process (Rogers, 1995). The phases underpinning the process of information system development (ISD) vary radically depending on the chosen methodology. There are, however, five basic activities or phases that are shared-albeit with different names - by 
most methodologies. These are: 1) identification and concept; 2) requirements definition; 3) system analysis and design; 4) implementation; and 5) testing and operation (Carugati, 2008).

The proposed model considers these activities of the SDLC methodology as examples of IS adoption in an organisational context. The SDLC is a traditional systems development methodology (see Figure 5.3) with a well-defined process for conceiving, developing and implementing an information system (Mahmood, 1987). Figure 5.3 illustrates these activities (with different names) carried out at each stage of the SDLC. It also highlights their relationship and interdependence. There are, however, problems of systems delivery and communication pertaining to the SDLC (Berrisford and Wetherbe, 1979; Gremillion and Pyburn, 1983) that we will address later.

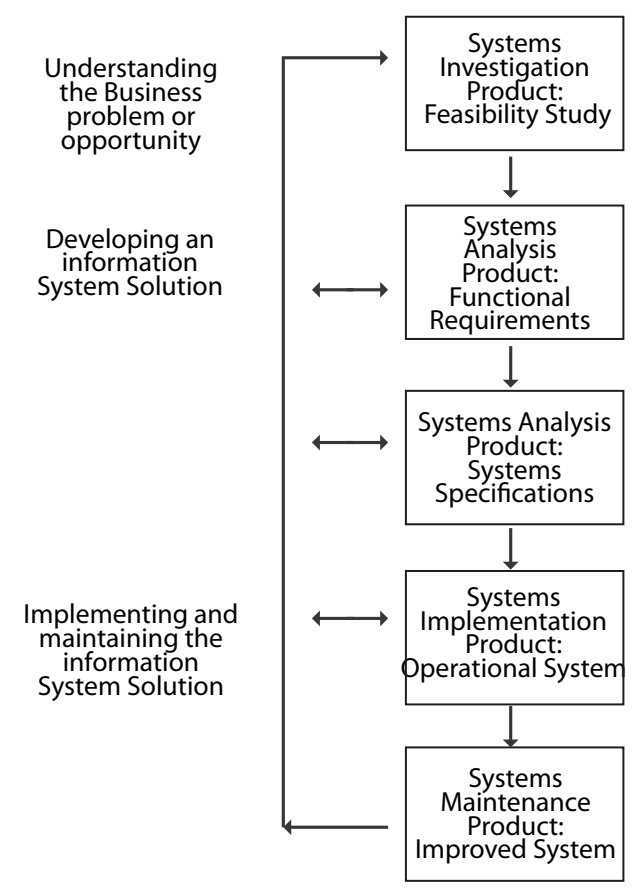

Determine how to address business opportunities and priorities. Conduct a feasibility study to determine whether a new or improved business system is a feasible solution. Develop a project management plan and obtain management approval.

Analyse the information needs of employees, customer, and other business stakeholders.

Develop the functional requirements of a system that can meet business priorities and the needs of stakeholders.

Develop specifications for the hardware, software, people, network and data resources, and the informational products that will satisfy the functional requirements of the proposed business information system.

Acquire (or develop) hardware and software. Test the system, and train people to operate and use it.

Convert to the new business system.

Manage the effects of system changes on end users.

Use a post-implementation review process to monitor, evaluate, and modify the business system as needed.

\section{Figure 5.3 The Traditional IS Development Cycle}

Source: O'Brien and Marakas (2005, p. 343).

We have adopted the SDLC as a roadmap for IS adoption progressing through its various phases, as shown in Figure 5.4. Figure 5.4 also shows that, on the basis of learning, IS project activities may be recycled back at any time to repeat previous activities with the aim of modifying and improving the system being developed (O'Brien and Marakas, 2005). 


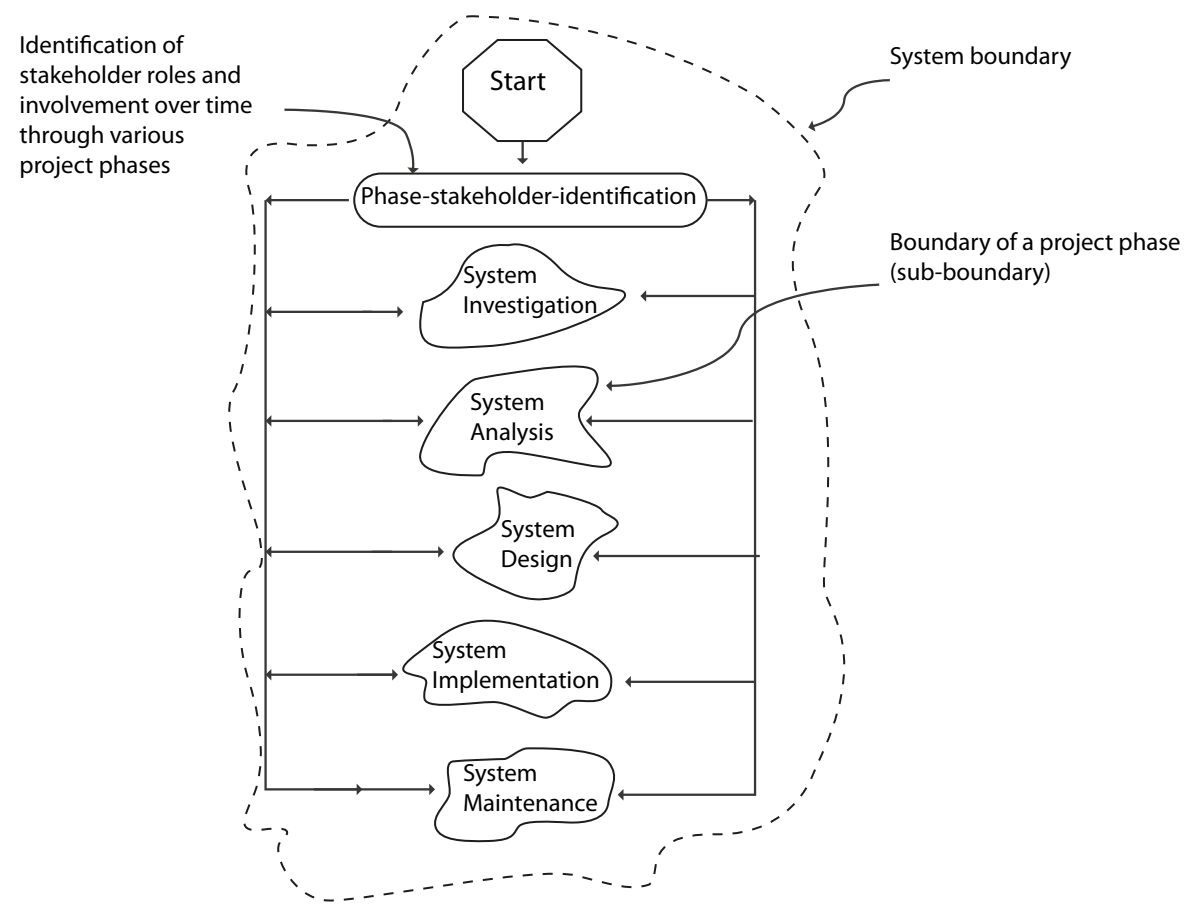

Figure 5.4 The Proposed Critical Systems Thinking-Based IS Adoption Model Using SDLC Phases

\section{Phase-Stakeholder-Identification Using Boundary Critique}

Identifying stakeholders, in the view of Vos (2003), is to draw a line between the parties to be involved and the parties not to be involved. Achterkamp and Vos (2007) propose a four-step method for project-based stakeholder identification using boundary critique that focuses on two key points: roles of involvement and phasing this involvement. They define a project broadly as an innovation project specially set up for pursuing the development of new products, services or processes (IS adoption, for instance), or a project concerning a (temporary) task inside or outside an organisation. The roles of involvement are underpinned by Ulrich's (1983) notion of boundary critique while phasing of involvement relates these roles to the dynamic processes of a project encompassing four phases of initiation, development, implementation and maintenance.

Based on the stakeholder roles defined by Achterkamp and Vos (2007), Table 5.1 defines the roles that stakeholders play in the context of the proposed model. The roles of stakeholders listed in the table fall into two main categories those involved and those affected (termed actively and passively involved respectively) - while the other roles might fall into either of these categories. In Figure 5.5, stakeholders W, X, Y, Z and, in Figure 5.6, stakeholders S, T, U, W, 
$\mathrm{X}, \mathrm{Y}$ and $\mathrm{Z}$ have been shown to exemplify those actively involved or passively involved (affected) and not playing the roles of a client (C), a decision maker (DM) or a designer (D). Client $\mathrm{C}$ has been shown at the intersection of the actively involved and passively involved (affected) stakeholders though this may vary across different project scenarios.

\section{Table 5.1 Roles of Involvement for IS Adoption}

\begin{tabular}{|c|c|}
\hline Role & Definition \\
\hline $\begin{array}{l}\text { Party involved actively } \\
\text { and passively (the } \\
\text { two basic categories) }\end{array}$ & $\begin{array}{l}\text { A party involved is any group or individual who } \\
\text { i. can affect the achievement of the project objectives (actively } \\
\text { involved) or } \\
\text { ii. is affected by the achievement of these objectives (passively } \\
\text { involved). }\end{array}$ \\
\hline Client (C) & $\begin{array}{l}\text { A client is a party whose purposes are being served through the } \\
\text { project. }\end{array}$ \\
\hline Decision maker (DM) & $\begin{array}{l}\text { A decision maker is responsible for } \\
\text { i. identifying business opportunities and priorities in relation to } \\
\text { the IS project } \\
\text { ii. conducting a feasibility study about the new or improved IS } \\
\text { iii. analysing the information needs of stakeholders } \\
\text { iv. setting requirements regarding the project processes and } \\
\text { outcomes and evaluating whether these requirements are met } \\
\text { v. managing the effects of system changes on end users } \\
\text { vi. establishing and/or revamping stakeholder networks for IS } \\
\text { diffusion } \\
\text { vii. monitoring and evaluating a post-implementation review. }\end{array}$ \\
\hline Designer (D) & $\begin{array}{l}\text { A designer contributes expertise within the IS project and is } \\
\text { responsible for the } \\
\text { i. (interim) deliverables } \\
\text { ii. development of a project management plan and its approval } \\
\text { iii. development of functional requirements that could meet the } \\
\text { business priorities and the needs of stakeholders } \\
\text { iv. development of specifications for the hardware, software, } \\
\text { people, network and data resources } \\
\text { v. system testing and user training } \\
\text { vi. modifications to the IS based on a post-implementation review. }\end{array}$ \\
\hline $\begin{array}{l}\text { Passively involved } \\
\text { representative }(R)\end{array}$ & $\begin{array}{l}\text { A passively involved representative is affected by the project } \\
\text { outcomes or project process without being able to influence the } \\
\text { process or these outcomes. A representative is a person who has } \\
\text { been chosen to act on behalf of another - that is, the passively } \\
\text { involved. }\end{array}$ \\
\hline
\end{tabular}

Unlike the four project phases identified by Achterkamp and Vos (2007), we consider IS adoption under the five basic activities of ISD (Carugati, 2008) or project phases as defined under the SDLC - namely, investigation, analysis, design, development and maintenance ( $\mathrm{O}^{\prime}$ Brien and Marakas, 2005). Moreover, based on the four-step stakeholder identification method suggested by Achterkamp and Vos (2007), we emphasise the ongoing requirement for identification of stakeholders and its repetition as required during the progress of the IS adoption project (see principle two), as shown in Figure 5.4. 
We term this phase-stakeholder-identification and it generates the systemic network of stakeholders (Figure 5.5) while its repetition sweeps-in more information based on the effectiveness of the strategies for innovation diffusion, applied in the previous cycle(s).

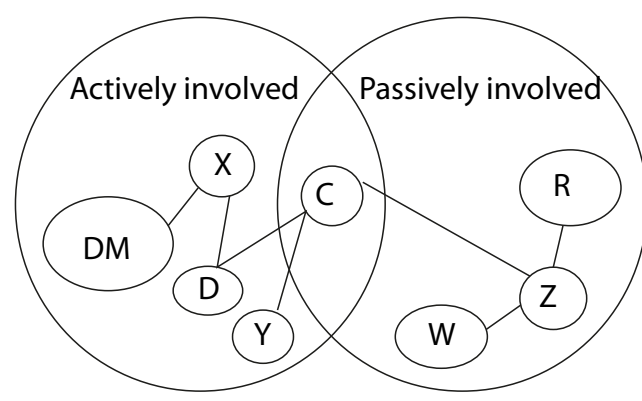

System Boundary

\section{Figure 5.5 Systemic Network of Stakeholders}

This repetition will eventually result in the redefinition of the boundaries under consideration, establishing the network of stakeholders as a function of time, as shown in Figure 5.6.

These networks emerging over time we call a systemic network of stakeholders. This model, based on the idea of progressive boundary refinement, consists of the following steps.

1. Define the goal of the project phase.

2. Identify stakeholders for each SDLC phase on the basis of phases of involvement (see Figure 5.6) and roles of involvement (see Table 5.1).

3. Represent stakeholders in the form of a systemic network of stakeholders over time (see Figures 5.5 and 5.6).

4. Apply network mechanisms (described in the next section) for influencing attitudes regarding IS adoption of the stakeholders in the network.

Since the SDLC phases have just been used to exemplify the five basic activities of ISD as identified by Carugati (2008), the process of phase-stakeholderidentification can also be coupled with methodologies other than the SDLC. The discussion here as to how this can be achieved has, however, been restricted due to space limitations. 


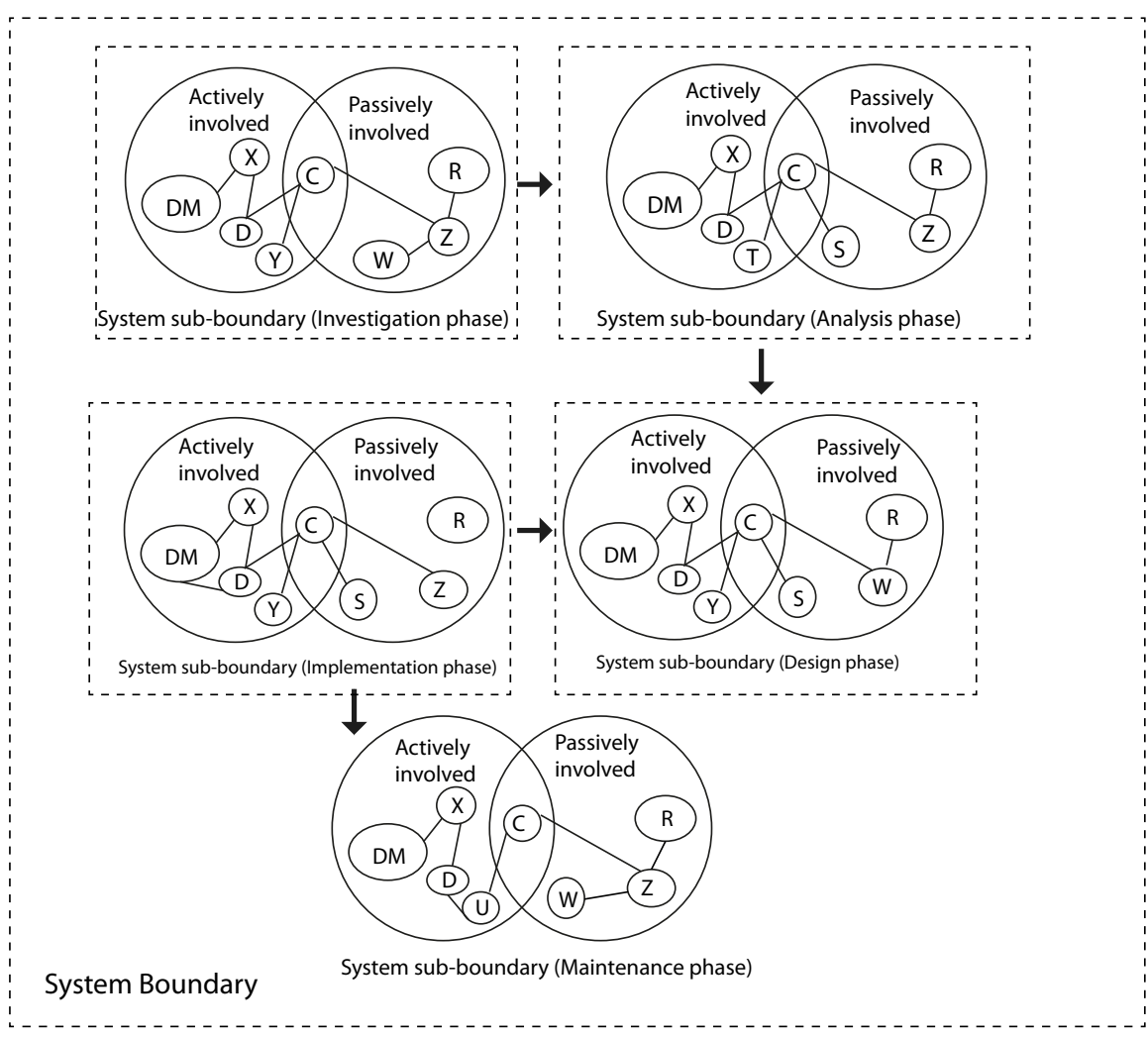

\section{Figure 5.6 Emergence of Systemic Stakeholder Networks Over Time Through Various SDLC Phases}

\section{Communication of Innovation}

Innovation diffusion, according to Rogers (1995), is the process by which an innovation is communicated among the members of a social system through certain channels over time. Accordingly, we now highlight the applicability of network mechanisms to the systemic network of stakeholders to influence opinions about the IS adoption process. The availability of information about the innovation and the communication processes heavily influences the diffusion process between the change proponents (the ones actively involved) and those who are affected (passively involved) by it (McIlduff and Coghlan, 2000).

As indicated by Cao et al. (2003), a shift in organisational form is tending to take place from rational bureaucratic composition towards a network-based configuration, characterised by a flatter authority structure. This configuration comprises multiple horizontal linkages between the inner core of a firm and its outside suppliers, contractors and customers (its stakeholders). This network of stakeholder relationships can be studied and analysed using social network 
analysis. This analysis has been used by researchers to refine and extend understanding of various behavioural and social phenomena, including community elite decision making, social influence, power and innovation diffusion (Cao et al., 2003; Rowley, 1997). According to Cummings and Worley (1993, p. 288), 'the network structure is highly flexible. Its components can be assembled and reassembled to meet changing conditions.'

For communicating information regarding IS adoption, we have emphasised the establishment of systemic networks of stakeholders (see Figures 5.5 and 5.6) over time by using 'boundary critique'. Network theorists argue that such networks influence perceptions and opinions and are capable of changing interpretations associated with and reducing uncertainty about an event, idea or phenomenon (Rogers and Kincaid, 1981). We argue that this capability of networks can be used in managing IS adoption and can influence perceptions of stakeholders about the process, and begin by providing a brief overview of the network mechanisms discussed in the literature.

Relational proximity or communication proximity views organisation as a communication network in which stakeholders repeatedly interact (directly and indirectly) to process resources and information (Dow, 1988, p. 56; Rogers and Kincaid, 1981). As mentioned by Erickson (1988), people are most likely to compare and agree with those to whom they are more strongly tied.

Positional proximity refers to the network of structurally proximate individuals who might not have links with one another as in relational proximity but they are linked to others with similar attributes like roles and obligations, status and expectations (Burt, 1980). 'Individuals may be the focus of similar information, requests and demands from members of their role set, creating an information field in which they are embedded' (Hartman and Johnson, 1989, p. 525).

Spatial proximity is based on the likelihood of interaction and exposure to social information due to living or working close together, which influences one's attitudes (Festinger et al., 1950). Unlike direct interaction, it can affect social information processing through exposure to or inaccessibility of the individuals to the organisational sub-climates, task materials and events (Hackman, 1983).

Together with these network mechanisms, we suggest the use of interventions for information propagation about IS adoption. In the context of innovation diffusion, an intervention is an action or event that influences (positively or negatively) the individuals involved or expected to be involved in the process (Hall and Hord, 1987, p. 143). McIlduff and Coghlan (2000, p. 724) view interventions as 'all conscious and deliberate actions and behaviours on the part of a manager, consultant or facilitator'. Our position is that network mechanisms combined with appropriate intervention strategies will influence the attitudes 
and behaviour of participants in conflict situations. The network mechanism will serve as a medium for information flow while the nature of intervention and the roles played by opinion leaders during these interventions will collectively determine the likelihood of innovation adoption success. Focusing on various intervention types is not, however, within the scope of this chapter. Hall and Hord (2006) provide a detailed discussion of various intervention sizes, functions, their levels and anatomy.

\section{Discussion}

Our model revolves around innovation diffusion in the context of IS adoption. Rogers (1995) considers members of the social system (people), communication channels and time to be the main ingredients of the innovation diffusion process. Azzara and Garone (2003) and Standing et al. (2006) regard the factors of the following list as key for the success of an IT/IS project

1. stakeholder support and involvement

2. project management and leadership

3. effective planning

4. executive commitment

5. project team commitment.

We now discuss how our model suggests these key factors might be addressed. The factors will be referred to in what follows as key factor one, key factor two, and so on.

As described above, our model has three main components: methodology, phase-stakeholder-identification and communication. Critical systems thinking (CST) is applicable in IS adoption due to its commitment to human/stakeholder involvement (key factor one) through the use of boundary critique. Moreover, IS adoption inside an organisation has impacts on its actions through its orientation to the roles and responsibilities of its stakeholders over time, and the adoption process will not prove successful until stakeholders and their roles are identified during the various phases governing IS adoption, based on the boundaries under consideration. The proposed model thus applies boundary critique over the time dimension, addressing key factor one.

Due to CST's handicap in providing guidance on issues like process reengineering, product quality improvement and applications development (Cao et al., 2003), the systems development life cycle (SDLC) has been used here to engage the methodological component of the model. It, in fact, has been used 
to serve as a roadmap for the IS adoption process and provides guidance to critically examine the progress of the whole project and the decision-making process. The reason for opting for a methodology for the IS adoption process can be justified as it keeps people focused on the proper tasks and activities required at a specific step of a transformation project (Paper et al., 2000). It serves as a rallying venue for cross-functional teams, facilitators and managers by keeping them informed regarding project progress (Kettinger et al., 1997), addressing key factors two and three.

Since diffusion of innovation is affected by the sources of information and channels of communication (Nilakanta and Scamell, 1990), the third component of communication is taken care of by the continuous determination of the stakeholder interactions in the form of systemic stakeholder networks that emerge over time as the IS adoption progresses through the SDLC phases. Singh (2005) has, for example, empirically shown the effectiveness of collaborative networks in knowledge flow and its diffusion.

Our argument is that repetition of defining/redefining stakeholders and their roles and the application of the network mechanisms to systemic stakeholder networks have the potential to serve as a rudder for the IS adoption process throughout the project life cycle (see Figure 5.6), resulting in effective communication management and in overcoming problems of systems delivery and communication pertaining to the SDLC (Berrisford and Wetherbe, 1979; Gremillion and Pyburn, 1983). This approach would show the commitment and concern of opinion leaders or executives and the project teams about the success of the IS adoption project by keeping the stakeholders (actively involved and passively involved) well informed about the project objectives and progress, addressing key factors one, four and five.

As shown in Figure 5.4, the SDLC has been coupled with phase-stakeholderidentification prior to each project phase. The irregular shapes illustrated around project phases (systems investigation, analysis, design, implementation and maintenance) represent each phase as an amoeba - a microscopic organism that has no specific shape and changes over time, emphasising the variable boundaries (sub-boundaries) of the project phases due to their continuous redefinition as the project progresses. The ability of these phase boundaries to expand, for sweeping-in relevant information, and to contract, to avoid its over-inclusion, makes phase-stakeholder-identification a rigorous ethical exercise. Moreover, like specific SDLC phases (investigation, analysis, design, development and maintenance), this process, based on learning, can also be repeated at any time, as required. This, in essence, does not damage the basic setting of the SDLC as a development methodology since project activities may be repeated at any time for modification and improvement of the system being developed $\left(\mathrm{O}^{\prime}\right.$ Brien and 
Marakas, 2005). Sweep-in thus becomes an integral part of the traditional SDLC, making it compulsory to define an ethically justified systemic stakeholder network before initiating a new IS adoption phase.

Thus, the process of phase-stakeholder-identification will help project managers to

- justify/redefine the roles (Table 5.1) and involvement (active or passive) of each stakeholder before a project phase is initiated (Figure 5.6)

- manage stakeholders by looking deeply into the interactions occurring inside the systemic stakeholder networks (Figure 5.5) employing social network mechanisms (Singh, 2005) and/or altering the network structures when required (Cummings and Worley, 1993)

- glide through various phases in, ideally speaking, a conflict-free environment or, at least, one that has a minimum of conflict

- address the problems of systems delivery and communication pertaining to the SDLC (Berrisford and Wetherbe, 1979; Gremillion and Pyburn, 1983) through clear definition of roles and responsibilities and communication management of stakeholder networks.

\section{Limitations and Conclusion}

Based on the preceding analysis and discussion, a practical procedure, incorporating critical systems thinking, network stakeholder theory and innovation diffusion, for systematically conducting the IS adoption project has been presented. The model, however, is not a wizard's wand for leading project managers to triumph. Rather, the proposed model is capable of assisting project managers along the road to success through addressing key factors that are essential for a successful IS adoption project.

Traditional approaches (like the SDLC) to IS development overemphasise the design and construction of computer-based artefacts without giving sufficient attention to the social and contextual sides of the process (Avison et al., 1998). A critical systems thinking perspective is beneficial for engaging these in IS adoption in an organisational context. Boundary critique and systemic stakeholder networks provide the knowledge base and the strategic view for managing stakeholder-related issues in IS adoption and their impact on organisations during innovation diffusion. Our model, however, still needs to be empirically tested. Its likely practicality, though, lies in the fact that CST, the SDLC and network mechanisms are procedures or methods that have previously been applied and tested in real-life scenarios. 
The model suggests the use of interventions to influence attitudes towards IS adoption to mitigate resistance. But it recommends neither any particular intervention plan nor any measure of effectiveness for an intervention strategy. It also does not provide a mechanism to indicate when these interventions transform from facilitating innovation diffusion to its manipulation.

The model uses the SDLC as a roadmap for an IS adoption project but we do not discuss how the proposed model can be modified to accommodate the phases associated with some other system development methodologies like rapid application development (RAD), joint application development (JAD), the spiral model, and so on. We also do not discuss its applicability or coupling with other technology acceptance models like TAM or TAM2; however, these two aspects are future research directions that can be taken in the development of such models.

\section{References}

Achterkamp, M. C., \& Vos, J. F. J. (2007). Critically identifying stakeholders. Evaluating boundary critique as a vehicle for stakeholder identification. Systems Research and Behavioral Science, 24(1), 3-14.

Ackoff, R. L. (1995). Whole-ing the parts and righting the wrongs. Systems Research and Behavioral Science, 12(1), 43-6.

Avison, D. E., Wood-Harper, A. T., Vidgen, R. T., \& Wood, J. R. G. (1998). A further exploration into information systems development: the evolution of Multiview2. Information Technology and People, 11(2), 124-39.

Azzara, C., \& Garone, S. (2003). IT adoption profiles and application implementation failures. Research report. AlignIT Group.

Berrisford, T. R., \& Wetherbe, J. C. (1979). Heuristic development: a redesign of systems design. MIS Quarterly, 3(1), 11-19.

Burt, R. S. (1980). Models of network structure. Annual Review of Sociology, 6, 79-141.

Cao, G., Clarke, S., \& Lehaney, B. (2003). Diversity management in organisational change: towards a systemic framework. Systems Research and Behavioral Science, 20(3), 231-42.

Carugati, A. (2008). Information system development activities and inquiring systems: an integrating framework. European Journal of Information Systems, 17(2), 143-55. 
Chen, J., \& Latendresse, P. (2003). The information age and why IT projects must not fail. Paper presented at the Thirty-Fourth Southwest Decision Sciences Institute Conference, Houston, Tex., March.

Churchman, C. W. (1970). Operations research as a profession. Management Science, 17(2), B37-53.

Churchman, C. W. (1979). The Systems Approach and Its Enemies. New York, NY: Basic Books.

Cooper, R., \& Markus, M. L. (1995). Human reengineering. Sloan Management Review, 36(4), 39-50.

Cummings, T. G., \& Worley C. G. (1993). Organization Development and Change. Minneapolis, Minn.: West Publishing.

Davis, F. D. (1989). Perceived usefulness, perceived ease of use, and user acceptance of information technology. MIS Quarterly, 13(3), 319-40.

Davis, F. D., Bagozzi, R. P., \& Warshaw, P. R. (1989). User acceptance of computer technology: a comparison of two theoretical models. Management Science, 35(8), 982-1002.

Dow, G. (1988). Configurational and coactivational views of organizational structure. Academy of Management Review, 13(1), 53-64.

Erickson, B. H. (1988). The relational basis of attitudes. In B. Wellman \& S. D. Berkowitz (eds), Social Structures: A network approach (pp. 99-121). Cambridge, UK: Cambridge University Press.

Festinger, L., Schacter, S., \& Back, K. (1950). Social Pressures in Informal Groups: A study of human factors in housing. Palo Alto, Calif.: Stanford University Press.

Freeman, R. E. (1984). Strategic Management: A stakeholder approach. Boston, Mass.: Pitman.

Freeman, R. E., \& Evan, W. M. (1990). Corporate governance: a stakeholder interpretation. The Journal of Behavioral Economics, 19(4), 337-59.

Gremillion, L. L., \& Pyburn, P. (1983). Breaking the systems development bottleneck. Harvard Business Review, 61(1), 130-7.

Hackman, J. R. (1983). Group influences on individuals. In M. D. Dunnette (ed.), Handbook of Industrial and Organizational Psychology (pp. 1455-525). New York, NY: Wiley. 
Hall, G. E., \& Hord, S. M. (1987). Change in Schools: Facilitating the process. Albany, NY: SUNY Press.

Hall, G. E., \& Hord, S. M. (2006). Implementing Change: Practices, principles and potholes. Boston, Mass.: Pearson.

Hartman, R. L., \& Johnson, J. D. (1989). Social contagion and multiplexity: communication networks as predictors of commitment and role ambiguity. Human Communication Research, 15(4), 523-48.

Jick, T. D. (1993). Managing Change: Cases and concepts. Homewood, Ill.: Irwin.

Kettinger, W. J., Teng, J. T. C., \& Guha, S. (1997). Business process change: a study of methodologies, techniques, and tools. MIS Quarterly, 21(1), 55-81.

Kroenke, D. M. (2009). Using MIS. Upper Saddle River, NJ: Prentice-Hall.

McIlduff, E., \& Coghlan, D. (2000). Understanding and contending with passiveaggressive behaviour in teams and organizations. Journal of Managerial Psychology, 15(7), 716-32.

Mahmood, M. A. (1987). System development methods - a comparative investigation. MIS Quarterly, 27(3), 293-311.

Malmsjö, A., \& Övelius, E. (2003). Factors that induce change in information systems. Systems Research and Behavioral Science, 20(3), 243-53.

Midgley, G. (2003). Science as systemic intervention: some implications of systems thinking and complexity for the philosophy of science. Systemic Practice and Action Research, 16(2), 77-97.

Midgley, G. (2007). Systems thinking for evaluation. In B. Williams \& I. Imam (eds), Systems Concepts in Evaluation: An expert anthology (pp. 11-34). Point Reyes, Calif.: Edge Press.

Nilakanta, S., \& Scamell, R. W. (1990). The effect of information sources and communication channels on the diffusion of innovation in a database development environment. Management Science, 36(1), 24-40.

O’Brien, J. A., \& Marakas, G. (2005). Introduction to Information Systems. New York, NY: McGraw-Hill.

Paper, D., Rodger, J., \& Pendharkar, P. (2000). Development and testing of a theoretical model of transformation. Proceedings of the 33rd Hawaii International Conference on Systems Sciences, 1-9.

Rogers, E. M. (1995). Diffusion of Innovations. [Fourth edn]. New York, NY: The Free Press. 
Rogers, E. M., \& Kincaid L. D. (1981). Communication Networks: Toward a new paradigm for research. New York, NY: The Free Press.

Rowley, T. J. (1997). Moving beyond dyadic ties: a network theory of stakeholder influences. The Academy of Management Review, 22(4), 887-910.

Singh, J. (2005). Collaborative networks as determinants of knowledge diffusion patterns. Management Science, 51(5), 756-70.

Standing, C., Guilfoyle, A., Lin, C., \& Love, P. E. D. (2006). The attribution of success and failure in IT projects. Industrial Management and Data Systems, 106(8), 1148-65.

Ulrich, W. (1983). Critical Heuristics of Social Planning: A new approach to practical philosophy. New York, NY: Wiley.

Venkatesh, V., \& Davis, F. D. (2000). A theoretical extension of the technology acceptance model: four longitudinal field studies. Management Science, 46(2), 186-204.

Venkatesh, V., Morris, M. G., Davis, G. B., \& Davis, F. D. (2003). User acceptance of information technology: toward a unified view. MIS Quarterly, 27(3), 42578.

Vos, J. F. J. (2003). Corporate social responsibility and the identification of stakeholders. Corporate Social Responsibility and Environmental Management, $10(3), 141-52$.

Waldman, J. N. (2007). Thinking systems need systems thinking. Systems Research and Behavioral Science, 24(3), 271-84.

Wilby, J. (2005). Combining a systems framework with epidemiology in the study of emerging infectious disease. Systems Research and Behavioral Science, 22(2), 385-98.

Yardley, D. (2002). Successful IT Project Delivery. London, UK: Pearson.

Zaltman, G., Duncan, R. B., \& Holbek, J. (1973). Innovations and Organizations. New York, NY: Wiley. 